\title{
Regulación de la dispensación de medicamentos y su efecto en el consumo de antibióticos en Venezuela
}

\author{
Phenélope Rivas ${ }^{1}$ y Guillermina Alonso ${ }^{1}$
}

Forma de citar

Rivas P, Alonso G. Regulación de la dispensación de medicamentos y su efecto en el consumo de antibióticos en Venezuela. Rev Panam Salud Publica. 2011;30(6):592-7.

RESUMEN Objetivo. Determinar las variaciones en la tendencia de consumo de los antibióticos regulados y no regulados en Venezuela, entre el período antes (2005) y después (2006-2008) de introducir la regulación de su venta por receta.

Métodos. Se obtuvo información sobre consumo de antibióticos en Venezuela de los datos aportados por International Marketing Services. El consumo se expresó en dosis diarias definidas por 1000 habitantes por día. Se realizaron análisis de varianzas (ANOVA) con un intervalo de confianza de $95 \%$ para conocer las diferencias entre los períodos estudiados.

Resultados. Losantibióticos regulados de mayor consumo fueron ciprofloxacina yazitromicina. Las clases de antibióticos no regulados de mayor consumo fueron penicilinas y cefalosporinas de primera generación, aminoglucósidos, diaminopiridinas-sulfamidas y tetraciclinas. El consumo total de las categorías de antibióticos de libre dispensación fue el doble del de las categorías de venta regulada, tanto antes como después de haberse aplicado la regulación.

Conclusiones. No se encontraron diferencias estadísticamente significativas en el consumo de antibióticos, ya fueran regulados o de libre dispensación, ni antes ni después de aplicarse la medida regulatoria de dispensación de antibióticos. Palabras clave Agentes antibacterianos; farmacorresistencia bacteriana; legislación de medicamen-
tos; utilización de medicamentos; Venezuela.

Con base en la determinación de la susceptibilidad microbiana en aislados clínicos, se han publicado diversos trabajos científicos que informan que el empleo inadecuado de antibióticos promueve la selección de cepas de bacterias resistentes. Esto deriva en un problema de salud pública mundial, ya que se reducen las opciones terapéuticas para tratar las infecciones; incrementan los gastos de la atención sanitaria, y aumenta la mortalidad (1-3). En años recientes, en Venezuela se

1 Universidad Central de Venezuela, Facultad de Ciencias, Instituto de Biología Experimental, Laboratorio de Biología de Plásmidos, Caracas, Venezuela. La correspondencia se debe dirigir a Guillermina Alonso, guillermina.alonso@ciens.ucv.ve han documentado cambios en la epidemiología de las infecciones nosocomiales. Además de los estudios del Grupo Venezolano de Resistencia Bacteriana (GVRB), el equipo de trabajo del Laboratorio de Biología de Plásmidos del Instituto de Biología Experimental de la Universidad Central de Venezuela ha realizado investigaciones sobre la caracterización de plásmidos de bacterias procedentes de diferentes ambientes del país (4-7). Estos estudios concluyen que las infecciones por bacterias resistentes a los antibióticos constituyen un problema de salud importante, especialmente las causadas por cepas de Pseudomonas spp., Acinetobacter spp., Klebsiella spp., Enterobacter spp., Pro- teus mirabilis, Escherichia coli, Enterobacter cloacae, Staphylococcus aureus, Streptococcus pneumoniae y Enterococcus (8-9).

Por otra parte, hace ya más de tres décadas que la Organización Mundial de la Salud (OMS) instó a sus Estados Miembros a adoptar medidas para limitar la diseminación de la resistencia a los antibióticos (10). En un taller internacional sobre contención de la resistencia bacteriana, delegaciones de 22 países concluyeron que la publicidad no regulada de los antibióticos por parte de la industria farmacéutica, sumada al incumplimiento de las políticas públicas sobre uso racional de medicamentos, estimula la prescripción y el autoconsumo 
y profundiza el problema de la resistencia a los antimicrobianos (11).

Como una estrategia para contener el aumento de la resistencia bacteriana en Venezuela, el 2 de enero de 2006, se publicó la resolución $N^{\circ} 604$ de la Gaceta Oficial Venezolana $\mathrm{N}^{\circ} 38.348$ mediante la cual la dispensación de medicamentos antimicrobianos en farmacias, servicios farmacéuticos y cualquier otro establecimiento debidamente autorizado debe realizarse mediante la presentación de la prescripción facultativa. Los medicamentos antimicrobianos aludidos en la resolución son aquellos de uso sistémico de las siguientes clases: fluoroquinolonas, macrólidos - lincosamidas, cefalosporinas de tercera generación, y aquellos cuyo principio activo sea rifampicina (www.camesip.org/documentos/ gaceta38348.pdf).

Dado que el conocimiento sobre el consumo de antimicrobianos en los diferentes ámbitos del sistema de salud es el paso inicial del diseño de intervenciones para mejorar la utilización de esos fármacos, el objetivo de esta investigación fue estudiar los posibles cambios derivados de la medida regulatoria de dispensación de antibióticos en la tendencia del consumo de antimicrobianos en Venezuela en el período del 1 de enero de 2005 al 31 de diciembre de 2008.

\section{MATERIALES Y MÉTODOS}

\section{Diseño}

Se realizó un estudio retrospectivo de utilización de medicamentos. Se compararon las cuatro clases de antimicrobianos regulados con las cuatro de venta libre con mayor consumo durante el período de estudio.

\section{Consumo de antibióticos}

La totalidad de especialidades farmacéuticas (todos los antibióticos en todas las presentaciones) correspondientes a los antibióticos dispensados en Venezuela entre el $1^{\circ}$ de enero de 2005 y el 31 de diciembre de 2008 fue facilitada por International Marketing Services - Health (IMS), cuyos datos han sido utilizados por diversos autores para realizar estudios de utilización de medicamentos en Europa y Latinoamérica (12-14). Se consultó el portal http://plm.wyeth.com.mx/ y el índice DDD/ATC 2011 (15) para conocer los componentes de los medicamentos que figuraban con su nombre comercial. Todos los antibióticos se agruparon según el principio activo y se clasificaron en las dos categorías mencionadas: regulados y no regulados. De la información de las presentaciones de cada fármaco, se desglosaron las dosis mínimas y el gramaje por unidad vendida.

La dosis mínima corresponde a la menor cantidad de fármaco que se puede consumir para una presentación determinada (16). El cálculo de los gramos de principio activo vendidos para cada presentación se realizó de la siguiente forma:

Unidades de envases vendidos $\times$ dosis mínima $\times$ gramos de cada presentación $=$ gramos de principio activo vendidos

Para obtener los gramos de los fármacos cuyo principio activo es penicilina $G$, se utilizó la unidad Oxford $(1 \mu \mathrm{g}$ de penicilina sódica equivale a 1667 unidades internacionales) (17).

Para los fármacos combinados se sumaron los gramos de cada principio activo constituyente.

Se utilizó como indicador de consumo la dosis diaria definida (DDD), que es independiente de las dosis ponderales de una especialidad farmacéutica; su valor corresponde a la dosis media diaria habitual de un fármaco cuando se utiliza para su indicación principal en adultos (18).

Para estimar la fracción de la población expuesta a cada clase de fármacos, el consumo medio se expresó en DDD por 1000 habitantes por día, como sigue (las DDD específicas se encuentran disponibles en: http:/ / www.whocc.no/atcddd/):

DDD $/ 1000$ habitantes $\times$ día $=[$ (g vendidos $\times 1000) /($ número días de estudio $\times$ DDD $\times$ población)]

\section{Análisis estadístico}

Se hizo una correlación lineal entre las variables DHD de todas las clases de antibióticos (regulados y no regulados) y los años del estudio con MS Excel ${ }^{\circledR}$ (2007) para calcular la tasa de cambio en el tiempo mediante la ecuación de la recta de mínimos cuadrados (19). Se llevaron a cabo análisis exploratorios de la varianza de un factor (ANOVA). Se utilizó un nivel de significancia de 0,05.

Al aplicar las pruebas estadísticas para comparar dos muestras poblacionales, se tomó la precaución de que dichas muestras incluyeran un mínimo de tres ré- plicas para que el resultado fuese digno de confianza (20). Aquellas categorías de antibióticos compuestas por un solo principio activo se analizaron descriptivamente mediante los gráficos.

\section{RESULTADOS}

\section{Antibióticos regulados}

En el cuadro 1 se muestra el consumo de los antibióticos regulados. Las clases de antibióticos con mayor consumo fueron macrólidos-lincosamidas y fluoroquinolonas; la azitromicina y la ciprofloxacina tuvieron las DHD más altas y la ceftazidima, la más baja.

En la figura 1 se muestra la tendencia del consumo de antibióticos regulados en el período 2005-2008, y se observa que en ninguna de las clases de antimicrobianos (macrólidos, cefalosporinas, etc.) la tendencia es decreciente. El consumo promedio de antibióticos regulados aumentó de 3,8 a 5,8 DHD, pero esta diferencia no fue estadísticamente significativa.

\section{Antibióticos no regulados}

Los aminoglucósidos, diaminopiridinas-sulfamidas, penicilinas, cefalosporinas de primera generación y tetraciclinas fueron las clases de antimicrobianos no regulados más utilizadas durante el período de estudio (cuadro 2).

Se sumaron las DHD de penicilinas y cefalosporinas de primera generación, ya que comparten los valores más altos de consumo y el mecanismo bacteriano de resistencia enzimático. Se obtuvo, en promedio, que 7,4 personas por 1000 habitantes habían consumido diariamente estos fármacos betalactámicos durante los años de estudio, cifra que es superior al consumo total promedio de todos los antimicrobianos regulados para el mismo período (cuadro 1). Los aminoglucósidos presentaron los valores de consumo más bajos. En promedio, 9,1 personas por 1000 habitantes consumieron la DDD de antibióticos no regulados diariamente, cifra que es el doble del promedio total (4,92 DHD) de consumo de los antimicrobianos regulados en el período estudiado (cuadro 1).

La figura 2 muestra la tendencia de consumo de los antibióticos no regulados. Las tetraciclinas y los aminoglucósidos no mostraron cambios en la tenden- 
CUADRO 1. Dosis diarias definidas por habitante por día (DHD) de los antibióticos regulados, ${ }^{\mathrm{a}}$ Venezuela, por año, 2005 a 2008

\begin{tabular}{|c|c|c|c|c|c|c|}
\hline \multirow[b]{3}{*}{ Familia } & \multirow[b]{3}{*}{ Antibiótico } & \multicolumn{5}{|c|}{ DHD } \\
\hline & & \multicolumn{4}{|c|}{ Año } & \multirow{2}{*}{$\begin{array}{c}\text { Total } \\
2005-2008\end{array}$} \\
\hline & & 2005 & 2006 & 2007 & 2008 & \\
\hline \multirow[t]{5}{*}{ Fluoroquinolona } & Ciprofloxacina & 1,15362 & 1,32483 & 1,48661 & 1,48535 & 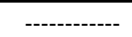 \\
\hline & Levofloxacina & 0,31941 & 0,53037 & 0,68964 & 0,87395 & ----------- \\
\hline & Moxifloxacina & 0,05269 & 0,06280 & 0,07683 & 0,09562 & ----------- \\
\hline & Norfloxacina & 0,12810 & 0,11895 & 0,10223 & 0,11104 & ---------- \\
\hline & Ofloxacina & 0,02346 & 0,02195 & 0,01935 & 0,01687 & - \\
\hline Total & & 1,67728 & 2,05890 & 2,37465 & 2,58283 & 8,69366 \\
\hline \multirow[t]{5}{*}{ Macrólido } & Azitromicina & 1,14619 & 1,36754 & 1,52450 & 1,73600 & ----- \\
\hline & Claritromicina & 0,47885 & 0,64412 & 0,69860 & 0,75950 & ----------- \\
\hline & Eritromicina & 0,23905 & 0,18485 & 0,17459 & 0,15011 & \\
\hline & Roxitromicina & 0,02807 & 0,02620 & 0,02226 & 0,01895 & ---- \\
\hline & Spiricina & 0,03279 & 0,03919 & 0,04203 & 0,04222 & 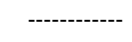 \\
\hline \multirow[t]{2}{*}{ Lincosamida } & Clindamicina & 0,09329 & 0,11659 & 0,17762 & 0,13754 & ----------- \\
\hline & Lincomicina & 0,01333 & 0,01323 & 0,01190 & 0,01031 & \\
\hline Total & & 2,03159 & 2,39173 & 2,65150 & 2,85463 & 9,92945 \\
\hline \multirow[t]{6}{*}{ Cefalosporina $3 G$} & Cefixima & 0,03716 & 0,06237 & 0,08748 & 0,10583 & ------------ \\
\hline & Ceftibuteno & 0,08918 & 0,12828 & 0,16896 & 0,20870 & \\
\hline & Cefotaxima & 0,00525 & 0,00395 & 0,00357 & 0,00364 & \\
\hline & Ceftazidima & 0,00094 & 0,00086 & 0,00093 & 0,00072 & ----------- \\
\hline & Ceftriaxona & 0,01287 & 0,01425 & 0,01641 & 0,01763 & \\
\hline & Cefoperazona & 0,00596 & 0,00519 & 0,00601 & 0,00394 & ----------- \\
\hline Total & & 0,15137 & 0,21490 & 0,28336 & 0,34046 & 0,99009 \\
\hline Rifampicina & Rifampicina & 0,01109 & 0,01228 & 0,01213 & 0,01218 & 0,04768 \\
\hline Promedio & --.-- & --------- & ----------- & ----------- & ---------. & 4,92 \\
\hline
\end{tabular}

a Gaceta Oficial Venezolana № 38348.

FIGURA 1. Consumo de antibióticos regulados, ${ }^{\mathrm{a}}$ en dosis diarias definidas por habitante por día (DHD), por año, 2005 a 2008

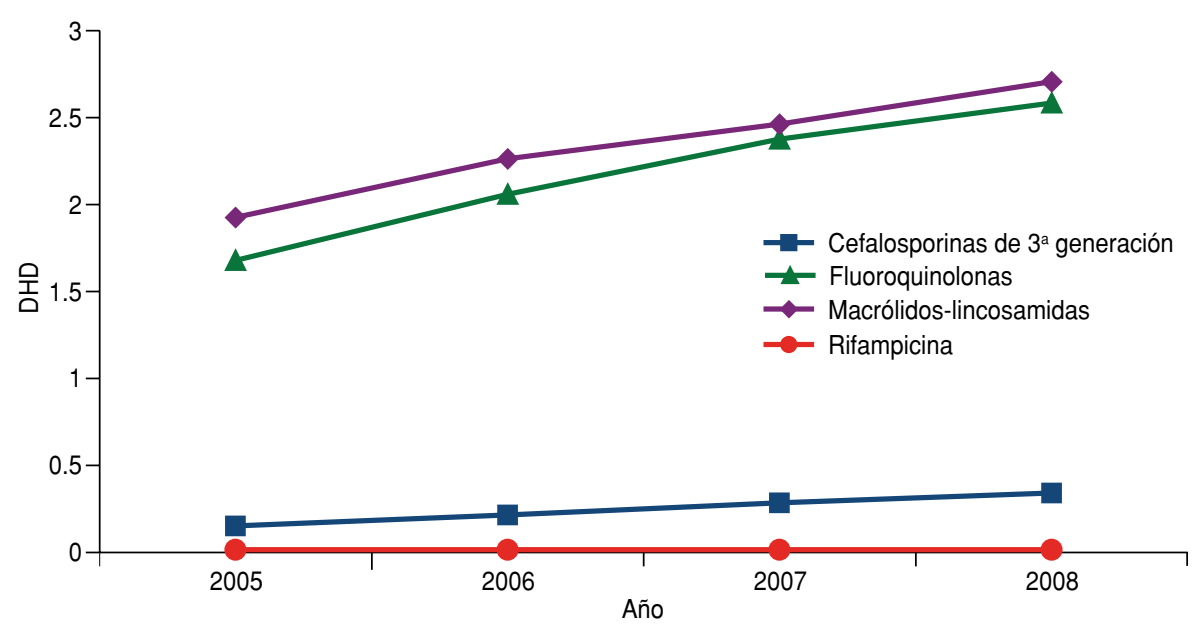

a Cefalosporinas de $3^{\mathrm{a}}$ generación, macrólidos-lincosamidas, fluoroquinolonas y rifampicina.

cia de consumo durante todo el período de estudio. El consumo de penicilinascefalosporinas de primera generación tuvo un crecimiento anual de 0,5 DHD.

El valor de probabilidad del estadístico $F$ de Fisher superó el valor crítico de
0,05 en todas las categorías no reguladas entre los períodos pre y posregulatorio. No hubo diferencias estadísticamente significativas entre el consumo de fármacos no regulados antes y después de la regulación.

\section{DISCUSIÓN}

Venezuela tiene una coyuntura compleja como resultado de la transformación del sistema de atención primaria de la última década. En el marco de la Constitución aprobada en 1999, en la cual se define la promoción de la salud como una prioridad, a partir de 2003 y hasta la fecha, se han habilitado más de 1600 consultorios populares que dispensan los fármacos directamente a las personas que asisten a las consultas. A la vez, y paradójicamente, en otros centros asistenciales más antiguos, se solicita al paciente que compre sus medicamentos porque en esos centros de salud no cuentan con ellos. Esta situación dificulta la obtención de cifras precisas del consumo de antibióticos en el país $(21,22)$ y sugiere que los datos presentados en este artículo podrían subestimar los valores reales del consumo, ya que no incluyen información oficial sobre el consumo de antibióticos proveniente del sector público.

Aunque el consumo de antibióticos de libre dispensación fue el doble del de los antimicrobianos regulados (véanse los cuadros 1 y 2), no se encontró relación entre ese hecho y la medida de control, puesto que la tendencia se mantiene para los períodos pre y posregulatorio en ambas categorías de medicamentos.

Es interesante resaltar que las disposiciones regulatorias implementadas por el Ministerio de Salud de Chile en septiembre de 1999 tuvieron un impacto inmediato en las ventas de antibióticos en ese país. El cumplimiento de la medida fue acompañado de la entrega de folletos en las farmacias privadas, carteles de publicidad y difusión por la prensa escrita, radio y televisión. También se informó a los directores técnicos de las farmacias acerca de la responsabilidad que les cabía en la aplicación de la regulación (12). Sin embargo, según un estudio sobre tendencias en el consumo de antibióticos en América Latina publicado en 2010, el impacto positivo de la regulación que en 1999 llevó a exigir a las farmacias la venta de antibióticos exclusivamente con receta médica sólo duró tres años. Mientras que en 1997 el consumo de antibióticos en Chile fue de 14 DHD, en 2002 bajó a cerca de 9,8 DHD, pero en 2007 repuntó a 12,5 DHD (14). La Comisión de Antimicrobianos de la Sociedad Chilena de Infectología informó que la razón del mayor uso no se debía a que en la 
CUADRO 2. Dosis diarias definidas por habitante por día (DHD) de los antibióticos no regulados, ${ }^{\mathrm{a}}$ por año, 2005 a 2008.

\begin{tabular}{|c|c|c|c|c|c|c|}
\hline \multirow[b]{3}{*}{ Categoría } & \multirow[b]{3}{*}{ Antibiótico } & \multicolumn{5}{|c|}{$\mathrm{DHD}$} \\
\hline & & \multicolumn{4}{|c|}{ Año } & \multirow{2}{*}{$\begin{array}{c}\text { Total } \\
2005-2008\end{array}$} \\
\hline & & 2005 & 2006 & 2007 & 2008 & \\
\hline $\begin{array}{l}\text { Cefalosporina } \\
1^{\mathrm{a}} \text { generación }\end{array}$ & Cefadroxilo & 0,0632 & 1,2430 & 1,2790 & 1,2548 & 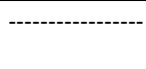 \\
\hline $\begin{array}{l}\text { Cefalosporina } \\
1^{\mathrm{a}} \text { generación }\end{array}$ & Cefalexina & 0,1345 & 0,1259 & 0,1179 & 0,0926 & ------ \\
\hline $\begin{array}{l}\text { Cefalosporina } \\
1^{a} \text { generación }\end{array}$ & Cefazolina & 0,0191 & 0,0213 & 0,0159 & 0,0095 & \\
\hline $\begin{array}{l}\text { Cefalosporina } \\
1^{a} \text { generación }\end{array}$ & Cefazolina & 0,0337 & 0,0153 & 0,0077 & 0,0061 & \\
\hline $\begin{array}{l}\text { Cefalosporina } \\
1^{a} \text { generación }\end{array}$ & Cafalotina & 0,0082 & 0,0035 & 0,0025 & 0,0020 & \\
\hline Penicilina & Ampicilina & 1,5529 & 1,7036 & 1,7149 & 1,8867 & - \\
\hline Penicilina & Amoxicilina & 2,5382 & 3,2073 & 3,3452 & 3,5022 & \\
\hline Penicilina & Sultamicilina & 0,6250 & 0,7937 & 0,9219 & 1,0558 & \\
\hline Penicilina & Penicilina G & 0,2575 & 0,2491 & 0,2006 & 0,1880 & \\
\hline Penicilina & Oxacilina & 0,1210 & 0,1309 & 0,0988 & 0,0854 & -------- \\
\hline Penicilina & Piperacilina & 0,0018 & 0,0010 & 0,0007 & 0,0007 & ----------------' \\
\hline Penicilina & Dicloxacilina & 0,0127 & 0,0099 & 0,0141 & 0,0095 & \\
\hline Penicilina & Flucoxacilina & 0,0064 & 0,0071 & 0,0057 & 0,0045 & 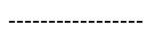 \\
\hline $\begin{array}{l}\text { Total penicilinas- } \\
\text { cefalosporinas } \\
1^{\text {a }} \text { generación }\end{array}$ & - --1-- & 6,3742 & 7,5116 & 7,7249 & 8,0978 & 29,70850 \\
\hline $\begin{array}{l}\text { Diaminopirimidina- } \\
\text { Sulfamida }\end{array}$ & $\begin{array}{l}\text { Trimetoprima- } \\
\text { sulfametoxazol }\end{array}$ & 1,1055 & 1,1043 & 1,0245 & 1,0113 & 4,24560 \\
\hline Tetraciclina & Oxitetraciclina & 0,3906 & 0,4626 & 0,5006 & 0,3520 & \\
\hline Tetraciclina & Limeciclina & 0,0624 & 0,0725 & 0,0842 & 0,0894 & 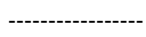 \\
\hline Tetraciclina & Tigeciclina & 0 & 0 & 0,0001 & 0,0001 & 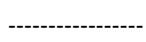 \\
\hline Total tetraciclinas & 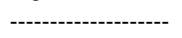 & 0,4530 & 0,5351 & 0,5849 & 0,4415 & 2,01450 \\
\hline Aminoglucósido & Amikacina & 0,0598 & 0,0605 & 0,0614 & 0,0605 & -------------- \\
\hline Aminoglucósido & Gentamicina & 0,0577 & 0,0625 & 0,0675 & 0,0663 & \\
\hline Aminoglucósido & Kanamicina & 0,0122 & 0,0117 & 0,0112 & 0,0076 & ---------------- \\
\hline Aminoglucósido & Dibekacina & 0,0020 & 0,0022 & 0,0023 & 0,0020 & \\
\hline Aminoglucósido & Netilmicina & 0,0032 & 0,0026 & 0,0007 & 0,0008 & ---------------- \\
\hline Aminoglucósido & Tobramicina & 0,0008 & 0,0008 & 0,0006 & 0,0005 & \\
\hline Total aminoglucósidos & ------------------- & 0,1357 & 0,1403 & 0,1437 & 0,1377 & 0,5574 \\
\hline Promedio & 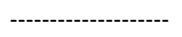 & (n) & --.---.--- & 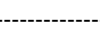 & - & 9,13 \\
\hline
\end{tabular}

FIGURA 2. Consumo de antibióticos no regulados, ${ }^{\mathrm{a}}$ en dosis diarias definidas por habitante por día (DHD), por año, 2005 a 2008

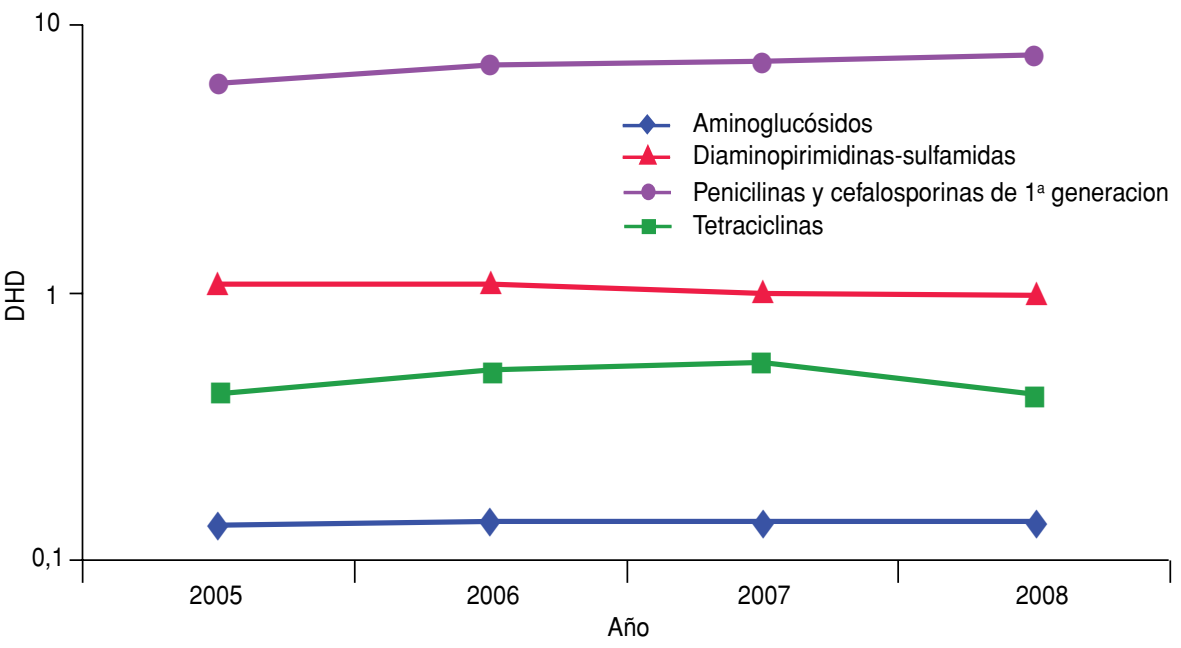

a Aminoglucósidos, diaminopiridinas-sulfamidas, tetraciclinas y penicilinas y cefalosporinas de $1^{\text {a }}$ generación. actualidad hubiera más infecciones que antes. Entre las causas del aumento de consumo se señala que las autoridades de salud "no han hecho más educación a la población ni han reforzado la fiscalización a las farmacias" (23).

Los resultados obtenidos por Bavestrello y colaboradores para las DHD de los antibióticos vendidos en Chile señalan que la amoxicilina es el fármaco de mayor consumo, con 5,57 DHD en 1998, su valor más alto (12). Castro y colaboradores encontraron un patrón similar, ya que la amoxicilina fue el antibiótico más consumido en Honduras y Nicaragua para el período 2004-2005, con valores de DHD de 1,5 y 2,1, respectivamente. En consecuencia, la prevalencia del consumo de penicilinas encontrada en nuestro estudio es coherente con la de otros países de Latinoamérica (24). El alto consumo de penicilinas se debe en gran medida a que se utilizan por automedicación. Es de hacer notar que, aunque en Chile se reguló la venta de todas las clases de antibióticos, la disminución del consumo en ese país se debió principalmente al control de las ventas de penicilina, ya que el consumo de macrólidos y fluoroquinolonas permaneció estable, supuestamente porque su venta se realiza solo bajo prescripción médica (12).

El artículo 226 de la Ley General de Salud de México regula la venta de medicamentos clasificados como grupo IV (donde se incluyen los antibióticos), que debe realizarse con prescripción médica. No obstante, el boletín de prensa emitido por el Instituto Nacional de Salud Pública de México en marzo de 2010 indica que, en la práctica, esta regulación no se hace cumplir y que difícilmente se podrá aplicar sin sensibilizar previamente a la población y al personal de las farmacias (25).

Las experiencias de Chile y México permiten sugerir dos razones principales para la ausencia de diferencias estadísticamente significativas en la venta de antimicrobianos en Venezuela antes y después de la norma que exige la receta médica. La primera se refiere a la desinformación de la población general sobre la medida de control y a la falta de seguimiento de su cumplimiento; la segunda corresponde al hecho de que las clases de antibióticos que más se consumen en Venezuela por automedicación no fueron objeto de la regulación (penicilinas y cefalosporinas de primera generación). 
Wirtz y colaboradores utilizaron los datos de consumo del IMS-Health para describir las tendencias de la utilización de antibióticos en ocho países de América Latina entre 1997 y 2007. Entre los resultados de ese estudio se destaca que, en 1997, México tuvo el mayor uso de antibióticos (15,69 DHD), seguido de Argentina (14,37 DHD) y Chile (14,07 DHD). Diez años más tarde, Argentina (16,64 DHD) y Venezuela (15,99 DHD) encabezaron la lista de países (14).

Según los resultados de nuestro trabajo, la sumatoria del consumo de todos los antibióticos (regulados y de libre dispensación) para 2007 fue de 15,62 DHD y el promedio de utilización para 2005-2008 fue de 14,78 DHD. Esta cifra mantiene a Venezuela como uno de los países de mayor consumo de antibióticos en América Latina.

Wirtz y colaboradores sugieren en su artículo que la reglamentación y el cumplimiento de la prohibición de la venta sin receta médica de ciertos antibióticos en Venezuela a principios de 2006 no parece haber tenido ningún efecto a corto plazo en el uso de antibióticos en general (14). Esta apreciación coincide plenamente con los resultados presentados en el presente estudio.

Es importante destacar que durante la búsqueda de información de consumo para este trabajo se encontraron diversas anomalías en el cumplimiento de la regulación, tales como: desconocimiento de la población general y del personal de salud (incluidos médicos y farmacéuticos) acerca de cuáles eran los antibióticos incluidos en la regulación; ausencia de un plan de seguimiento por parte del Ministerio del Poder Popular para la Salud de dicha norma, y ausencia de personal que exija las prescripciones facultativas retenidas en las farmacias y establecimientos que dispensan medicamentos.

Como consecuencia de la escasez de información, no fue posible utilizar datos de consumo suministrados por instituciones del Estado venezolano, lo que limitó el número de años utilizados en la comparación entre el consumo pre y posregulatorio en este trabajo.

\section{Conclusiones}

Venezuela es uno de los primeros países latinoamericanos que ha puesto en efecto una medida regulatoria de dispensación de antibióticos; sin embargo, cinco años después de su emplazamiento, los resultados de este trabajo ponen en evidencia la ausencia de cambios en las tendencias de consumo de antimicrobianos.

Se deben implementar estrategias complementarias a la regulación de la dispensación de antibióticos en Venezuela para lograr el éxito de dicha medida.

Agradecimientos. Este trabajo fue financiado por el Consejo de Desarrollo Científico y Humanístico de la Universidad Central de Venezuela (CDCH) a GA (PG-03-7327).

\section{REFERENCIAS}

1. Alonso A, Álvarez-Sala R, Prados C, Mayoralas $\mathrm{S}$, Villamor J. Empiema adquirido en la comunidad por Acinetobacter baumannii. An Med Interna (Madrid). 2001;18(10):529-30.

2. Plascencia L, Aldama A, Vázquez H. Vigilancia de los niveles de uso de antibióticos y perfiles de resistencia bacteriana en hospitales de tercer nivel de la Ciudad de México. Salud Publica Mex. 2005;47(3):219-26.

3. Yoneyama H, Katsumata R. Antobiotic resistance in bacteria and its future for novel antibiotic development. Biosci Biotechnol Biochem. 2006;70(5):1060-107.

4. Narváez P, Pedroza R, Alonso G, Rodríguez Lemoine V. Caracterización de plásmidos de resistencia a antibióticos en aislados nosocomiales del Hospital Universitario de Caracas. Rev Soc Ven Microbiol. 2005;25(1):29-34.

5. Redondo C, Alonso G. Plásmidos conjugativos aislados de cepas multirresistentes de pacientes de cuatro centros de salud del área metropolitana de Caracas. Rev Soc Ven Microbiol. 2007;27(2):100-7.

6. Guzmán M, Alonso G. Integrones Clase I asociados a plásmidos en cepas de Klebsiella pneumoniae. Rev Soc Ven Microbiol. 2008;28(2):105-9.

7. Guzmán M, Alonso G. Caracterización de la región variable de integrones clase 1 presentes en cepas nosocomiales de Klebsiella pneumoniae, Cumaná, Estado Sucre, Venezuela. Rev Med Chile. 2010;138(3):322-9.

8. Comegna M, Guzmán M, Carmona O, Molina M, GVRB. Resistencia bacteriana a los antimi- crobianos en Venezuela - Nuevos hallazgos. Rev Soc Ven Microbio. 2000;20(1):58-63.

9. Grupo Venezolano de Resistencia Bacteriana. Actualización de los datos de resistencia bacteriana a los antimicrobianos en Venezuela. Período julio 2001-diciembre 2002. Rev Soc Ven Microbiol. 2003;23(1):89-97.

10. Organización Mundial de la Salud. Vigilancia para prevenir y combatir los riesgos secundarios provocados por las enterobacterias resistentes a los antibióticos. Serie de Informes Técnicos $\mathrm{N}^{\circ}$ 624. 1978.

11. Taller internacional conteniendo la resistencia bacteriana: reflexionar, compartir y armonizar para una acción coordinada. Facultad de Ciencias Médicas, Universidad de Cuenca, Ecuador. 2008. Disponible en http://www. reactgroup.org/uploads/who-we-are/rla/ the-cuenca-declaration-spanish.pdf Acceso el 19 de septiembre de 2011.

12. Bavestrello L, Cabello A, Casanova D. Impacto de medidas regulatorias en la tendencia de consumo comunitario de antibióticos en Chile. Rev Méd Chile. 2002;130(11): 1235-72.

13. Pastor E, Eiros J, Mayo A. Descripción del consumo diferencial de macrólidos por áreas geográficas en la provincia de Valladolid. Enferm Infecc Microbiol Clin. 2002;20(10):498502.

14. Wirtz V, Dreser A, Gonzales R. Trends in antibiotic utilization in eight Latin American countries, 1997-2007. Rev Panam Salud Publica. 2010;27(3):219-25.
15. WHO Collaborating Centre for Drug Statistics Methodology Norwegian Institute of Public Health website (ATC/DDD Index 2011).)

16. IMS-Health - Venezuela. 2005-2008. Pharmaceutical Market. International Market Statistics, IMS Health AG, Cham, Suiza.

17. Martín E, Cook F. Farmacia Práctica de Remington. Segunda edición UTEHA. Editorial Hispano-América; 1975.

18. Capellá D, Laporte JR. Métodos aplicados en estudios descriptivos de utilización de medicamentos, en Laporte, JR; Tognoni, G. 1993. Principios de epidemiología del medicamento, Editorial Masson-Salvat, $2^{\mathrm{a}}$ edición.

19. Gómez F. Estadística aplicada. Ediciones Fragor. Edición ampliada; 1998.

20. Programa Venezolano de la Vigilancia de la Resistencia Bacteriana a los Antimicrobianos. Disponible en: http://www.Provenra.org Acceso el 30 de abril de 2010.

21. Ministerio del Poder Popular para las Relaciones Exteriores. Comisión de Enlace para la Internacionalización de las Misiones Sociales. Disponible en: http://ceims. mre.gob.ve/index.php?option $=$ com_co ntent\&view $=$ article \&catid $=23$ : misiones bolivarianas\&id=39:mision-barrio-adentro-iii-iii-iv Acceso el 13 de abril de 2010.

22. El Universal. [Sitio en Internet]. En el Periférico de Coche se sienten abandonados. Disponible en: http://caracas.eluniversal. com/2010/04/13/ccs_art_en-el-perifericode_1846127.shtml) Acceso el 13 de abril de 2010 . 
23. Bavestrello L, Cabello A. Consumo comunitario de antimicrobianos en Chile, 2000-2008. Rev Chil Infectol. 2011;28(2):107-12.

24. Castro J, Hara G, Muñoz S, Castro M, Berríos $\mathrm{M}$, Montenegro A, et al. Consumo de antibióticos en Nicaragua y Honduras. Análisis de aspectos metodológicos y principales re- sultados. Rev Panam Infectol. 2008;10(4 Supl 1):104-11.

25. Regulación y promoción para el uso adecuado de antibióticos en México: Lineamientos para la acción. Instituto Nacional de Salud Pública. Boletín de prensa. Marzo 2010. Disponible en: http://www.amimc.org.mx/ noticias.htm Acceso el 20 de septiembre de 2011.

Manuscrito recibido el 6 de abril de 2011. Aceptado para publicación, tras revisión, el 16 de noviembre de 2011.

ABSTRACT Objective. Determine the variations in consumption trends for regulated and unregulated antibiotics in Venezuela in the period before (2005) and after (2006-2008) the regulation of prescription sales was introduced.

Regulations governing the dispensing of medications and their effect on antibiotic consumption in Venezuela
Methods. Information on antibiotic consumption in Venezuela was obtained from the data provided by International Marketing Services. Consumption was expressed in daily doses per 1000 inhabitants. Analyses of variance (ANOVA) were performed, with a 95\% confidence interval, to identify the differences between the periods studied. Results. The regulated antibiotics with the highest consumption were ciprofloxacin and azithromycin. The classes of unregulated antibiotics with the highest consumption were penicillins and first-generation cephalosporins, aminoglycosides, diaminopyridine-sulfonamides, and tetracyclines. Total consumption in the categories of antibiotics with unregulated dispensing was twice as high as in the categories with regulated sales, both before and after introduction of the regulation.

Conclusions. There were no statistically significant differences in antibiotic consumption with regulated or unregulated dispensing, either before or after the introduction of measures regulating the dispensing of antibiotics.

Key words Anti-bacterial agents; drug-resistance, bacterial; legislation, drug; drug utilization; Venezuela. 